\title{
Algumas considerações sobre o ritmo, o metro e a rima de La Pipa de Kif, de Ramón María del Valle-Inclán (1866- 1933)
}

\author{
Vicente Masip (UFPE) \\ Oussama Naouarii (UFPE)
}

\begin{abstract}
Resumo: Celebra-se, em 2019, o centenário da primeira edição da obra La pipa de Kif, de Ramón María del Valle Inclán. O poemário convida a infindáveis abordagens de todo tipo: rítmicas, métricas, léxicas, morfossintáticas e estilísticas, pois a sua riqueza formal e funcional é imensurável. Esperam-se numerosas reflexões, artigos, ensaios e resenhas em obras monográficas, revistas e periódicos, especialmente no universo do mundo hispânico. Neste breve artigo, decidimos focar apenas alguns aspectos, no intuito de participar do mutirão internacional em andamento.

Palavras chave: Lírica, Prosódia, ritmo, métrica, rima.
\end{abstract}

\begin{abstract}
The centennial of the first edition of Ramón María del Valle Inclán's work La pipa de Kif is celebrated in 2019. The Valle-Inclán poemery invites endless approaches of all kinds: rhythmic, metric, lexical, morphosyntactic and stylistic, since the formal and functional wealth it holds is immeasurable. Countless reflections, articles, essays and reviews are expected in monographic works, magazines and periodicals, especially in the universe of the Hispanic world. In this brief article, we decided to focus only on metric and rhythmic aspects, in order to participate in the ongoing international effort.
\end{abstract}

Keywords: Lyric, Prosody, rhythm, metric, rhyme.

\section{Introdução}

A comunicação humana é complexa. O modo de olhar, de andar ou de sentarse são significativos; podem sugerir cansaço, nervosismo, alegria, tristeza... Nossos gestos ou sinais detêm uma dimensão, externa y observável, e mensagens que serão 
interpretadas segundo o filtro do observador, pois não são unívocas. A Semiologia é a ciência que se dedica ao seu estudio (SAUSSURE, 2006, p. 23-25).

A linguagem verbal é diferente. Quando falamos, emitimos mensagens codificadas em signos linguísticos ${ }^{1}$, compostas de um número limitado de fonemas ${ }^{2}$, e prosodemas3, veiculados por sons, que transmitem conteúdos cognitivos mediante palavras ${ }^{4}$. A Semiótica se encarrega da sua análise (MORRIS, 1966, p. 61-71).

Quando a mensagem linguística supera a mera convenção significativa, lógica e funcional do código, e é transformada pela dimensão estética, surge a linguagem simbólica ou literária. Se a literatura é o clímax da língua, pois consegue transmitir uma mensagem codificada, falada ou escrita, de modo estético, a poesia é a máxima expressão literária, dado que destrói a dicotomía inerente à mensagem, que reside na sua dupla manifestação sonora e cognitiva, harmonizando-as e realizando-as em plenitude (MASIP, 2002, p. 27-32).

\section{Poesia portuguesa e espanhola: sistemas métricos e rítmicos diversos}

Eutomia é uma revista linguística e literária, editada pelo Departamento de Letras da Universidade Federal de Pernambuco, Brasil. Consideramos oportuno esclarecer algumas diferenças métricas e rítmicas entre a poesia portuguesa ( $A L I$, 1999; MOISÉS, 2000; TAVARES, 1996; BARBOSA, 2000) e espanhola (BOUSOÑO, 1985; DOMINGUEZ, 1993; HERRERO, 1996; LÓPEZ, 1987; OUILIS, 1981; TOLEDO, 1988), para que o falante de português consiga ler com fruto os poemas de ValleInclán.

\footnotetext{
${ }^{1}$ Convenções próprias de um determinado código natural de comunicação oral (MASIP, 2014:V-vii)

${ }^{2}$ Mínimas unidades fonológicas distintivas, divisíveis (cf. MASIP, 2014: 5-79).

3 Conjuntos de tom, intensidade e duração, não divisíveis (cf. MASIP, 2014: 80-130).

4 Sistema fonológico/fonético português. Fonemas: /i e $\varepsilon$ a $ว$ o u p b t d k g f v s z $\int 3 \mathrm{~m} \mathrm{n} \mathrm{n} \mid \lambda$ r R/ e prosodemas de tom, intensidade e duração (cf. MATTOSO, 1977 e CUNHA, 1985). Sistema fonológico/fonético espanhol. Fonemas: /i e a o u p b t d k g f $\theta$ s y $x \mathrm{t} \int \mathrm{m} \mathrm{n} \mathrm{nl} \lambda \mathrm{r} r$ / e prosodemas de tom, intensidade e duração (cf. LLORACH, 1991 e QUILIS, 1991).
} 


\section{1 Sílaba ortográfica e sílaba métrica}

No ato de escrever, dividimos as frases em palavras. Falamos e declamamos, porém, de modo corrido, pronunciando vários vocábulos em uma única emissão de voz. No agrupamento dos sons, observa-se uma oscilação de frequência, denominada juntura (QUILIS, 1981; MASIP, 2002, p. 31-32); caracteriza-se por uma elevação de tom, quando arranca de uma vogal tônica, e por sua disminuição, quando se origina de uma vogal átona, contribuindo extraordinariamente com a melodia do verso (MASIP, 2002, p. 32-34).

A sílaba ortográfica, em português e espanhol, possui sempre uma vogal como

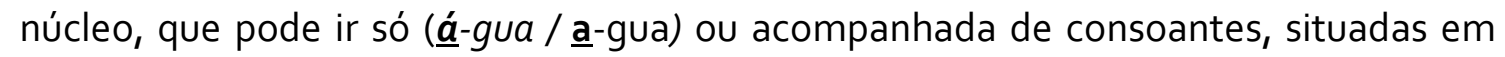
ataque (início de sílaba) ou coda (fim de sílaba) (pe-na, trans-por-tes), de semivogais, situadas imediatamente depois do núcleo silábico (cai-o / cai-go), ou de semiconsoantes, situadas imediatamente antes do núcleo silábico, existentes unicamente em espanhol: nieto (neto), nueve (nove) (MASIP, 2006, p. 5; 2014, p. 6).

A sílaba métrica espanhola, que segue o modelo italiano, tem os mesmos traços que a sílaba ortográfica, isto é, contam-se todas as sílabas, inclusive a átona final, mas as fronteiras grafêmicas se ultrapassam, devido à juntura. Assim, uma sílaba métrica pode se formar com letras de mais de uma palavra ortográfica. Vejamos, por exemplo, estes versos da primeira letrilha do poema Poderoso caballero es Don Dinero (Poderoso cavaleiro é Dom Dinheiro), de Francisco de Quevedo y Villegas (15801645)5: "Madre, yo al oro me humillo/ él es mi amante y mi amado,/ pues, de puro enamorado,/ de continuo anda amarillo" (Mãe, eu ao ouro me rendo/ é meu amante e amado,/ pois, de puro apaixonado,/ de contínuo anda amarelo). A divisão silábica da estrofe, segundo a norma ortográfica espanhola, é: "Ma-dre-yo-al-o-ro-me-hu-mi-llo (10) - él-es-mi-a-man-te-y-mi-a-ma-do, (11) - pues-de-pu-ro-e-na-mo-ra-do, (9) - decon-ti-nuo-an-da-a-ma-ri-llo". (10). A divisão silábica, pela métrica espanhola, porém, devido ao agrupamento de sons ou juntura, é: Ma-dre-yoa-lo-ro-mehu-mi-llo" (8)/ éles-mia-man-tey-mia-ma-do, (8)/ pues-de-pu-roe-na-mo-ra-do, (8)/ de-con-ti-nuoanda-ma-ri-llo. (8)

5 Uma das versões, anterior a 1603, desta letrilha encontra-se em ESPINOSA, 2005, p. 79-81. A versão 'definitiva' está em QUEVEDO, 1999, p. 674-676 e em QUEVEDO, 2002, p. 222225 . 
A sílaba métrica portuguesa, além da invasão ortográfica das sílabas, detém um traço inexistente em espanhol: só se contam as sílabas até a última tônica, seguindo o modelo francês, como se comprova ao declamar o primeiro quarteto deste soneto: "Quem aos olhos dar-me-á uma vertente/ de lágrimas que manem noite e dia?/ Ao menos a alma, enfim, respiraria,/ chorando, ora o passado, ora o presente?" (SÁ MIRANDA 1481-1558, 1970). A divisão silábica da estrofe, segundo a norma ortográfica portuguesa, é: "Quem-a-os-o-lhos-dar-me-á-u-ma-ver-ten-te (13) - de-lágri-mas-que-ma-nem-noi-te-e di-a? (12) - Ao-me-nos-a-al-ma-en-fim-res-pi-ra-ri-a, (13) - cho-ran-do-o-ra-o-pas-sa-do-o-ra-o-pre-sen-te?" (15). A divisão silábica métrica portuguesa, todavia, é: Quem-ao-so-lhos-dar-me-áu-ma-ver-ten (te) (10)/ de-lá-grimas-que-ma-nem-noi-te-di (a)? (10)/ Ao-me-no-sal-maen-fim-res-pi-ra-ri (a), (10)/ cho-ran-do-rao-pa-ssa-do-rao-pre-sen (te)? (10)

A norma métrica portuguesa parece mais complexa que a espanhola, mas é, pelo contrário, mais simples, pois segue sempre o mesmo critério: contam-se as sílabas até o último acento prosódico, desprezando as restantes. Já o espanhol computa todas as sílabas ortográficas se a última palavra do verso é paroxítona, mas retifica o critério quando o verso acaba em palavra oxítona ou proparoxítona; no primeiro caso, acrescenta-se uma sílaba métrica e, no segundo, subtrai-se uma. Observemos esta canção popular anônima: “¿Qué había dentro del cántaro, / morena de azul añil, / que un bando entero de pájaros / vino volando hasta aquí?" (O que havia dentro do cántaro, morena de azul anil, que um bando inteiro de pássaros veio voando até aqui?): ¿Quéha-bí-a-den-tro-del-cán-ta-ro, (9 -1=8)/ mo-re-na-dea-zu-la-ñil, $(7+1=8) /$ queun-ban-doen-te-ro-de-pá-ja-ros (9 -1=8)/ vi-no-vo-lan-dohas-ta-quí? $(7+1=8)$

\section{2 O ritmo poético.}

É o resultado sonoro de emissão vocálica, articulação consonantal, tom (altura, melodia e cadência), intensidade (acento e modulação) e quantidade (duração e pausas).

Dáctilo. É o pé métrico ou ritmo silábico acentual espanhol e português. Remonta aos pentâmetros e hexâmetros latinos, modelos de versificação, 
constituidos de sílabas longas e breves. Nas nossas línguas, mudou apenas o critério de clasificação do ritmo silábico: consideramos a tonicidade em lugar da quantidade.

\begin{tabular}{|l|l|l|l|}
\hline & & \multicolumn{1}{|c|}{ Latim } & \multicolumn{1}{|c|}{ Espanhol - Portugués } \\
\hline \multirow{4}{*}{$\begin{array}{c}\text { Dáctilo } \\
\text { (pé rítmico) }\end{array}$} & Jâmbico & Sílabas: breve, longa & Átona, tônica \\
\cline { 2 - 4 } & Troqueu & Sílabas: longa, breve & Tônica, átona \\
\cline { 2 - 4 } & Espondeu & Sílabas: longa, longa & Tônica, tônica \\
\cline { 2 - 4 } & Dactílico & Sílabas: longa, breve, breve & Tônica, átona, átona \\
\cline { 2 - 4 } & Anfibráquico & Sílabas: breve, larga, breve & Átona, tônica, átona \\
\cline { 2 - 4 } & Anapéstico & Sílabas: breve, breve, longa & Átona, átona, tônica \\
\hline
\end{tabular}

O conjunto de um hexâmetro e de um pentâmetro dactílicos resulta em um dístico elegíaco, a construção poética predileta do poeta latino Publio Ovidio Naso (43 a.C.-17 ou 18 d.C.) (OVID, 2018): Cum repeto noctem, qui tot mihi cara reliquil Labitur ex oculis nunc quoque gutta meis. (Quando lembro a noite em que deixei tantas coisas queridas, ainda agora uma lágrima escorre dos meus olhos.)

\begin{tabular}{|c|c|c|c|c|c|c|}
\hline Cum re pe & to noct & $e m, q u$ & i tot mi hi & ca $\underline{\text { ra }} \underline{\text { re }}$ & qui & \\
\hline 1 & 2 & 3 & 4 & 5 & 6 & \\
\hline$-\cup \cup$ & -- & -- & $-\cup \cup$ & $-\cup \cup$ & - - & $\mid \subset$ \\
\hline$\underline{\text { La }}$ bi tur & $\underline{\text { ex }} \underline{\mathrm{o}} \underline{\mathrm{CU}}$ & $\underline{\text { lis }}$ & unc quo qu & e gu tta $\underline{m}$ & me is & \\
\hline 1 & 2 & $1 / 2$ & 3 & 4 & $1 / 2$ & \\
\hline$-\cup \cup$ & $-\cup \cup$ & - & $-\cup u$ & $-\cup \cup$ & $\cup 1-$ & $\subseteq$ \\
\hline
\end{tabular}

Alguns poetas de língua espanhola imitam o metro latino: Esteban Manuel de Villegas (1589-1669), Sinibaldo de Mas (1809-1868), Juan Gualberto González (18511912), José Eusebio Caro (1817-1853), Salvador Rueda (1857-1933) e, especialmente, Rubén Darío (1867-1933, aliás, grande amigo de Valle-Inclán), o mais competente, segundo os críticos. Mesmo que o esforço de Rubén Darío seja admirável, o hexâmetro latino não produz um efeito sonoro estético em espanhol (tampouco em português); soa artificial, rimbombante, marcial, excesivamente cadenciado ${ }^{6}$.

\footnotetext{
6 "Ínclitas razas ubérrimas, sangre de España fecunda,/ espíritus fraternos, luminosas almas, jsalve!/ Porque llega el momento en que habrán de cantar nuevos himnos/ lenguas de gloria. Un vasto rumor llena los ámbitos;/ mágicas ondas de vida van renaciendo de pronto:/ retrocede el olvido, retrocede engañada muerte." (Inclitas raças ubérrimas, sangue de Espanha fecunda,/ espíritos fraternos, luminosas almas, ;salve!/ Porque chega o momento em que haverão de cantar novos hinos/ línguas de glória. Um vasto rumor enche os âmbitos;/ mágicas ondas de vida vão renascendo de pronto:/ retrocede o olvido, retrocede enganada morte.) (DARÍO, 1981)
} 
demais); entre colchetes, o período rítmico interior; seguida de um parêntese, a anacrusa (Nem sempre está presente.); precedido de um parêntese, o período de enlace.

A segunda teoria sobre o ritmo poético, de BONNIN (1996) e QUILIS (1997), defende que a estrofe é uma unidade melódica que possui um acento axial ou estrófico, formado pelo acento final de cada verso de uma mesma estrofe ou série de versos. Neste trabalho, adotaremos a abordagem proposta por Navarro Tomás, por considerá-la mais consistente e funcional.

\section{3 Tipos de versos}

De arte menor, inferiores a oito sílabas métricas espanholas (sete portuguesas) e de arte maior, superiores a nove sílabas métricas espanholas (oito portuguesas)

\section{4 Rima}

Todas as composições de Valle-Inclán detêm, sob o critério do timbre ${ }^{8}$, rima perfeita ou soante, que se caracteriza pela coincidência total de sons a partir da última sílaba; sob o critério da quantidade, rima feminina (paroxítona) ou masculina (oxítona); finalmente, sob o critério da disposição, a rima é, umas vezes, contínua (AAAA) e outras, encadeada (ABAB), emparelhada (AABB), abraçada (ABBA) ou interpolada (AABCCB) (MASIP, 2002, p. 42-47).

\section{Algumas considerações sobre ritmo, metro e rima de La Pipa de Kif 9}

Uma vez estabelecidos os parâmetros rítmicos, métricos e relativos à rima, é chegado o momento de abordar os dezoito poemas de La pipa de Kif ${ }^{10}$, sob a ótica castelhana, com o objetivo de detectar e diagnosticar o perfil significante da obra, isto é, a sua imagem acústica substancial (emissão, articulação e concatenação de sons) e

\footnotetext{
${ }^{8}$ Efeito acústico que resulta de uma fonte sonora e do receptáculo onde se produz.

9 Não traduzimos as estrofes escolhidas da obra, pois nosso objetivo é formal, visando unicamente a dimensão significante (imagem acústica).

${ }^{10}$ A editora Sociedad General Española de Librería de Madri lançou a obra de Valle-Inclán em 1919.
} 
formal (organização interna). Decidimos analisar as primeiras estrofes dos dezoito poemas, porque estabelecem de modo unívoco o modelo escolhido para cada série poética e são representativas das demais, salvo contadas exceções. As setas indicam entonação ascendente $(\uparrow)$, descendente $(\downarrow)$ ou em suspensão $(\rightarrow)$; e os filetes, pausa curta ( | ) ou prolongada ( | | $)^{11}$.

\section{1 La Pipa de Kif}

Con rítmicos saltos plenos de alegría,/ Cabalga en el humo de mi pipa Puk,/Su risa en la entraña de la luz del día/ Mueve el ritmo órfico amado de Gluk.



Ritmo. Versos de arte maior. Copla manriquenha, resultado da união de duas sextilhas (MASIP, 2002, p. 76). Período rítmico interior:

- O $1^{\circ}$ verso, misto: um dactílico e três troqueus, com anacrusa: o) [ó o o / ó o / ó o / ò o] (ó o.

- O $2^{\circ}$ verso, misto: um dactílico e três troqueus, semelhante ao $1^{\circ}$, com anacrusa: o) [ó o o / ó o / ò o / ó o] (ó.

- O $3^{\circ}$ verso, misto: um dactílico e três troqueus, semelhante aos dois primeiros, com anacrusa: o) [ó o o / ó o / ò o / ó o] (ó o.

- O $4^{\circ}$ verso, misto: dois troqueus e dois dactílicos, sem anacrusa: [ó o / ó o / ó o o / ó o o] (ó.

Rima soante, feminina, masculina e encadeada.

\section{2 iAleluya!}

Por la divina primavera/ Me ha venido la ventolera/ De hacer versos funabulescos - Un purista diría grotescos-.

\footnotetext{
${ }^{11}$ Convém esclarecer que setas e filetes devem ser considerados apenas um suporte, sugerido pelo autor deste artigo, para auxiliar a declamação, isto é, não fazem parte da composição poética propriamente dita.
} 


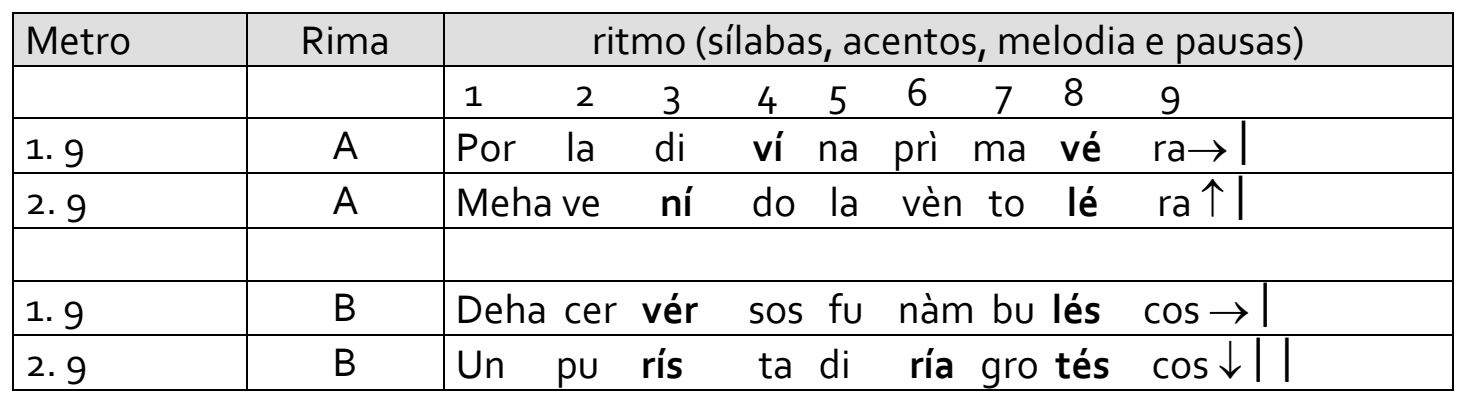

$\underline{\text { Ritmo. }}$ Versos de arte maior. Duas parelhas de eneassílabos com cesura ${ }^{12}$ marcada. Período rítmico interior:

- O $1^{\circ}$ verso é um conjunto de 2 troqueus, com anacrusa: o o o) [ó o / ò o] (ó o.

- O $2^{\circ}$ verso é misto: 1 dactílico e 1 troqueu, com anacrusa: o o) [ó o o / ò o] (ó o.

- O $3^{\circ}$ verso também é misto, conjunto de 1 dactílico e 1 troqueu, com anacrusa, de perfil rítmico equivalente ao $2^{\circ}: 0$ o) [ó o o / ò o] (ó o.

- $\mathrm{O} 4^{\circ}$ verso também é misto, conjunto de 1 dactílico e 1 troqueus, com anacrusa; difere do $2^{\circ}$ e do $3^{\circ}$ pela diversa tonicidade do troqueu: o o) [ó o o/ ó o] (ó o.

Rima soante, feminina e emparelhada.

\section{3 Fin de Carnaval}

Es miércoles de ceniza./ Fin de carnaval./Tarde de lluvia inverniza/ Reza el funeral.

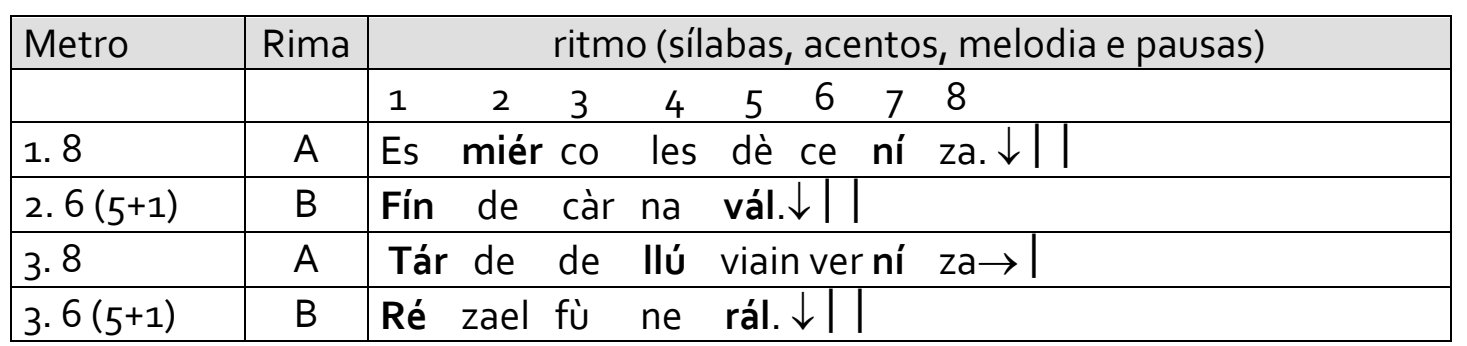

Ritmo. Versos de arte menor. Estrofe de versos octossílabos e hexassílabos, mistura de quarteta e seguidilha (MASIP, 2002, p. 71). Período rítmico interior:

- O $1^{\circ}$ verso é misto: 1 dactílico e 1 troqueu, com anacrusa: o) [ó o o / ò o] (ó o.

- O $2^{\circ}$ verso é o conjunto de 2 troqueus, sem anacrusa: [ó o / ò o] (ó o.

- O $3^{\circ}$ verso é o conjunto de 2 dactílicos, sem anacrusa: [ó o o / ó o o/] (ó o.

- $\mathrm{O} 4^{\circ}$ verso é o conjunto de 2 troqueus, sem anacrusa, equivalente ao $2^{\circ}$ : [ó o / ò o] (ó o.

Rima soante, feminina, masculina e encadeada.

\footnotetext{
${ }^{12}$ Pausa interna de um verso ou poema (cf. Masip, 2002: 40).
} 


\section{4 Marina Norteña}

Pasa el gato sonando las botellas/ De un anaquel de pino por lo alto:/ El cielo raso tiene dos estrellas/Pintadas, y una luna azul cobalto.

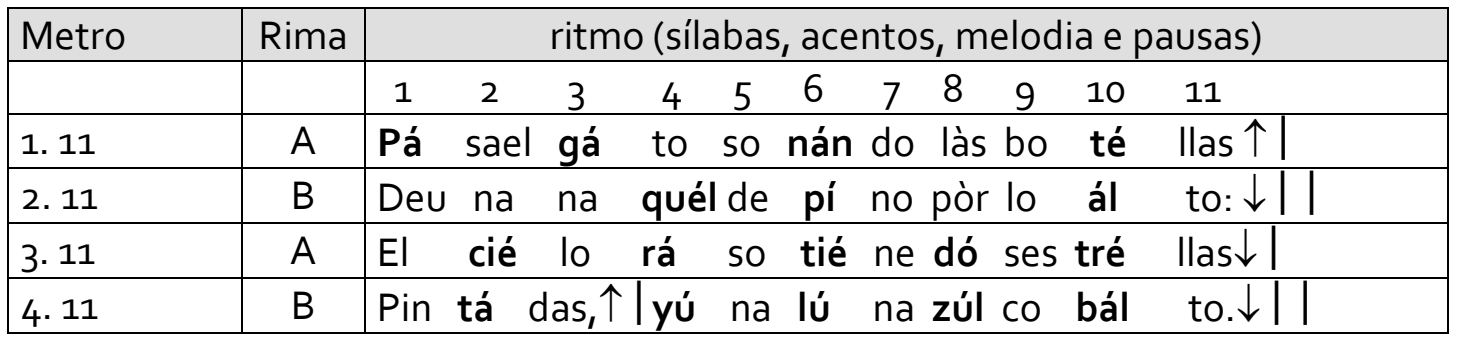

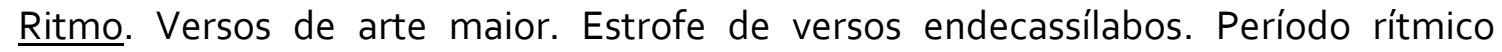
interior:

- O $1^{\circ}$ verso é misto: 1 dactílico e 3 troqueus, sem anacrusa: [ó o / ó o o / ó o / ò o] (ó O.

- O $2^{\circ}$ verso é um endecassílabo a minori, sáfico (acentos sobre as sílabas 4, 6, 8 e 10): conjunto de 3 troqueus, com anacrusa: o o o [ó o / ó o / ò o] (ó o.

- $\quad 3^{\circ}$ verso é um endecassílabo a maiori, heroico (acentos nas sílabas 2, 4, 6, 8, 10), conjunto de 4 troqueus, com anacrusa: o) [ó o / ó o / ó o / ó o] (ó o.

- $\mathrm{O}_{4}^{\circ}$ verso é um endecassílabo a maiori, heroico (acentos nas sílabas 2, 4, 6, 8, 10), conjunto de 4 troqueus, com anacrusa, equivalente ao $3^{\circ}$, mas acrescido de hemistíquio (MASIP, 2002, p. 62-63): o [ó o / ó o / ó o / ó o] (ó o.

Rima soante, feminina e encadeada.

\section{5 Bestiario $^{13}$}

Y me detuve emocionado/ Ante aquel viejo carcamal/ Estilizado/ En el escudo nacional.

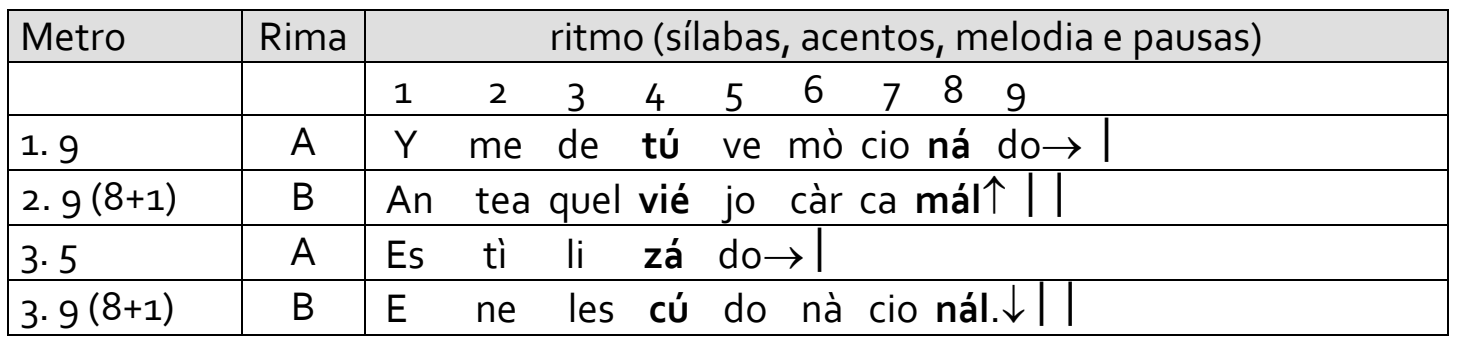

Ritmo. Estrofe composta de três versos de arte maior, eneassílabos, e um, de arte menor, pentassílabo, de combinação métrica original $(9+9+5+9)$, pois foge aos padrões. Período rítmico interior:

- $\mathrm{O} 1^{\circ}$ verso se compõe de 2 troqueus, com anacrusa: o o o [ó o / ò o] (ó o.

\footnotetext{
${ }^{13}$ Escolhemos a segunda estrofe deste poema porque a primeira excede o padrão.
} 
- O $2^{\circ}$ verso é o conjunto de 2 troqueus, com anacrusa: o o o [ó o / ò o] (ó, semelhante ao $1^{\circ} ;$ só difere daquele porque a sua última palavra é oxítona.

- O $3^{\circ}$ verso: 1 troqueu, com anacrusa: o) [ò o] ó o.

- O $4^{\circ}$ verso: 2 troqueus, com anacrusa, equivalente ao $2^{\circ}:$ o o o [ó o / ò o] (ó.

Rima soante, feminina, masculina e encadeada.

\subsection{El Circo de Lona}

Este poema se compõe de três capítulos

Primeiro capítulo de El circo de lona ${ }^{14}$ :

3. 6. 1 El agrio y desvencijado/Organillo, se atropella:/ Golfo viejo enamorado/De una estrella.

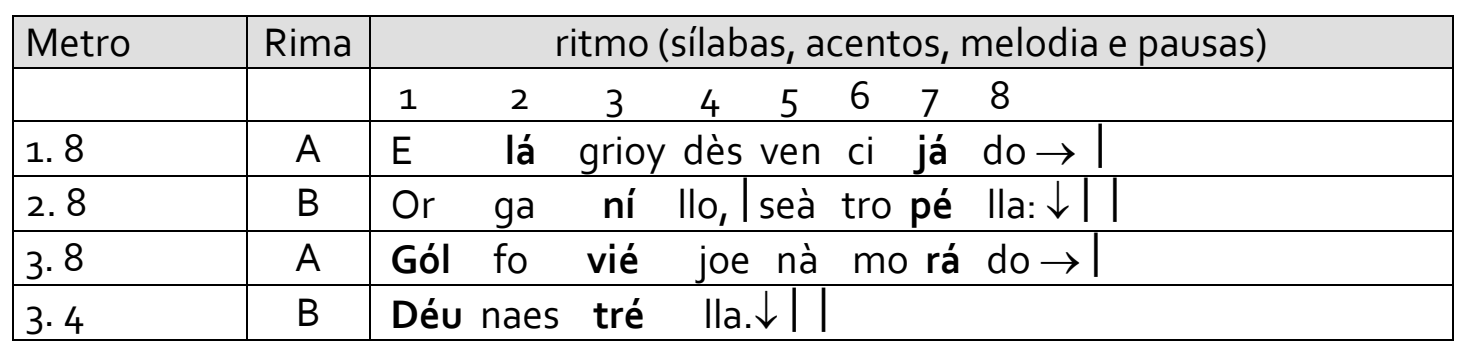

Ritmo. Estrofe composta de quatro versos de arte menor: três octossílabos e um, tetrassílabo; trata-se de uma quarteta de pé quebrado (MASIP, 2002, p. 71) $)^{15}$. Período rítmico interior:

- O $1^{\circ}$ verso é misto: 1 troqueu e 1 dactílico, com anacrusa: o [ó o / ò o o] (ó o.

- O $2^{\circ}$ verso: 2 troqueus, com cesura e anacrusa: o o [ó o / ò o] (ó o.

- O $3^{\circ}$ verso se compõe de 3 troqueus, sem anacrusa: [ó o / ó o / ò o] (ó o.

- $\mathrm{O}_{4^{\circ}}$ verso consta de 1 troqueu, sem anacrusa: [ó o] (ó o.

Rima soante, feminina e encadeada.

O segundo capítulo de El circo de lona detém um padrão diferente do primeiro:

3.6.2 Ríen dos gitanas,/Caras africanas,/ Dos verdes manzanas/De oriental jardín./ Luces de claveles,/ Flecos, arambeles,/ Hablar por babeles/Y no tener fin.

\footnotetext{
${ }^{14}$ Escolhemos a segunda estrofe do primeiro capítulo, porque a primeira excede o padrão.

${ }^{15} \mathrm{~A}$ estrofe que tem um verso menor que os demais chama-se "de pé-quebrado".
} 


\begin{tabular}{|c|c|c|}
\hline Metro & Rima & ritmo (sílabas, acentos, melodia e pausas) \\
\hline & & 345 \\
\hline 1.6 & A & Rí en dós gi tá nas, $\rightarrow$ \\
\hline 2.6 & A & ra sà fri cá nas, $\uparrow \mid$ \\
\hline 3.6 & A & Dós ver dès man zá nas $\rightarrow$ \\
\hline $4.6(5+1)$ & B & Deò rien tál jar dín. $\downarrow||$ \\
\hline 5.6 & C & Lú ces dè cla vé les, $\rightarrow$ \\
\hline 6.6 & $\mathrm{C}$ & Flé co s,à ram bé les, $\uparrow \mid$ \\
\hline 7.6 & C & Ha blár por ba bé les $\rightarrow$ \\
\hline $8.6(5+1)$ & $\mathrm{B}$ & Y nó te ner fin. $\downarrow||$ \\
\hline
\end{tabular}

Ritmo. Estrofe composta de oito versos de arte menor: todos hexassílabos; trata-se de duas redondilhas menores (MASIP, 2002, p. 71). Período rítmico interior:

- O $1^{\circ}$ verso: 2 troqueus sem anacrusa: [ó o / ó o] (ó o.

- O $2^{\circ}$ verso: 2 troqueus, sem anacrusa: [ó o / ò o] (ó o.

- O $3^{\circ}$ verso: 2 troqueus, sem anacrusa, equivalente ao 20: [ó o / ò o] (ó o.

- O $4^{\circ}$ verso: 2 troqueus, sem anacrusa: [ò o / ó o] (ó.

- O $5^{\circ}$ verso: 2 troqueus, sem anacrusa, equivalente ao $2^{\circ}$ e $3^{\circ}$ : [ó o / ò o] (ó o.

- O $6^{\circ}$ verso: 2 troqueus, sem anacrusa, equivalente ao $2^{\circ}, 3^{\circ}$ e $5^{\circ}$ : [ó o / ò o] (ó o.

- O $7^{\circ}$ verso: 1 dactílico, com anacrusa: o [ó o o] (ó o.

- O $8^{\circ}$ verso: 1 dactílico, com anacrusa: o [ó o o] (ó.

Rima soante, feminina, masculina e contínua.

O terceiro capítulo de El circo de lona segue um padrão semelhante ao primeiro (3. 6. 1):

3. 6. 3 Candileja de bencina,/Lloroso cabo de vela,/Sombra que se encalabrina/Por la tela.

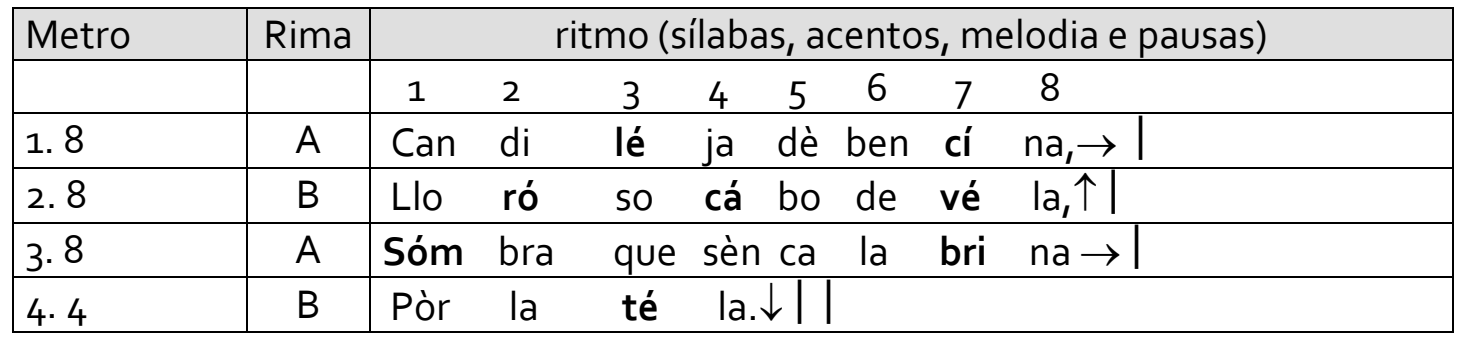

Ritmo. Estrofe composta de quatro versos de arte menor: três octossílabos e um, teatrassílabos; é uma quarteta de pé quebrado (cf. 2.6.1). Período rítmico interior:

- $O 1^{\circ}$ verso é o conjunto de 2 troqueus com anacrusa: o o [ó o / ò o] (ó o.

- O $2^{\circ}$ verso é misto: 1 troqueu e 1 dactílico, com anacrusa: o [ó o / ó o o] (ó o.

- O $3^{\circ}$ verso se compõe de 2 dactílicos, sem anacrusa: [ó o o / ò o o] (ó o.

- $\mathrm{O} 4^{\circ}$ verso consta de 1 troqueu, sem anacrusa: [ò o] (ó o.

Rima soante, feminina, contínua e encadeada. 


\section{7 El Jaque de Medinica}

La llama arrebola la negra cocina;/ Pone maritornes magras de cecina/ En las sopas cáusticas de ajo y pimentón./ El jaque se vuelve templando el guitarro,/ A la moza tose por que sirva un jarro/Y oprime los trastes pulsando el bordón.

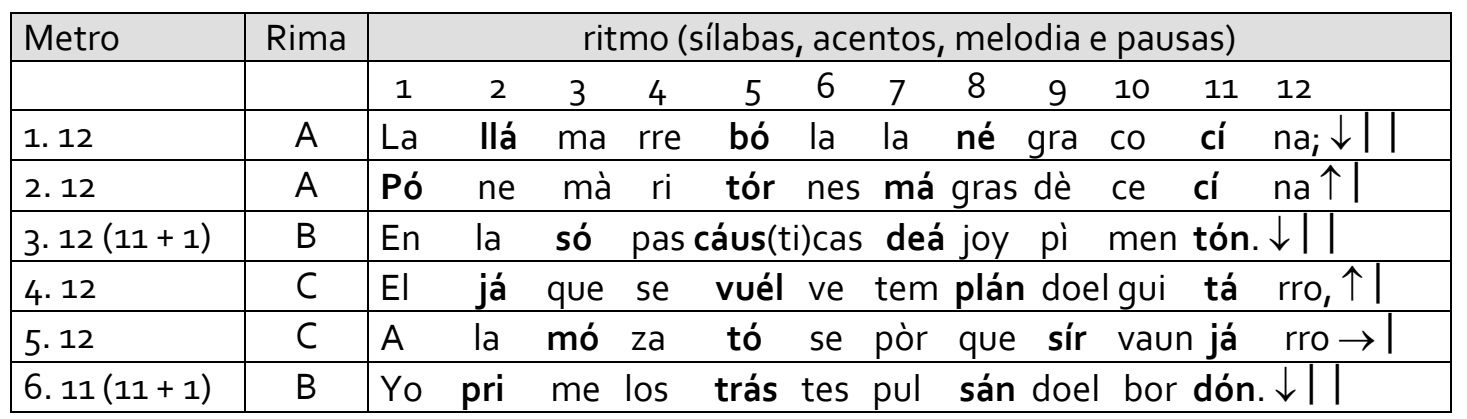

Ritmo. Estrofe composta de seis versos de arte maior: todos dodecassílabos, simétricos 6+6 (MASIP, 2002, p.64), compostos de dois hemistíquios (com acentos primários na primeira sílaba tônica de cada um); trata-se de um sexteto oxítono (MASIP, 2002, p. 64). Período rítmico interior:

- O $1^{\circ}$ verso: 3 dactílicos com anacrusa: o [ó o o/ ó o o / ó o o] (ó o.

- O $2^{\circ}$ verso: 5 troqueus, sem anacrusa: [ó o / ò o/ó o / ó o / ò o] (ó o.

- O $3^{\circ}$ verso: 4 troqueus, com anacrusa: o o [ó o / ó o / ó o / ò o] (ó. Este verso tem uma particularidade: a palavra "cáusticas", por ser proparoxítona, subtrai uma sílaba na contagem geral.

- O $4^{\circ}$ verso: 3 dactílicos, com anacrusa, equivalente ao $1^{\circ}$ : o [ó o o / ó o o / ó o o] (ó 0 .

- O $5^{\circ}$ verso: 4 troqueus, com anacrusa: o o [ó o / ó o / ò o / ó o] (ó o.

- O 60 verso: 3 dactílicos, com anacrusa: o [ó o o/ ó o o/ ó o o] (ó.

Rima soante, feminina, masculina e interpolada.

\section{8 Medinica}

Un pueblo con soportales/Y balcones de madera,/ Casas de adobe, corrales,/ Cigüeñas y rastrojera.

\begin{tabular}{|c|c|c|c|c|c|c|}
\hline Metro & Rima & \multicolumn{5}{|c|}{ ritmo (sílabas, acentos, melodia e pausas) } \\
\hline & & 2 & 5 & 67 & 8 & \\
\hline 1.8 & A & Un pué bl & o con sò & por tá & les $\rightarrow$ & \\
\hline 2.8 & $B$ & bal cc & nes dè & ma dé & $\mathrm{ra}, \uparrow \mid$ & \\
\hline 3.8 & A & Cá sas dea & dó be, & co rrá & les, $\rightarrow$ & \\
\hline 4. 8 & $\mathrm{~B}$ & $\mathrm{Ci}$ güé $\tilde{n}$ & s'y ras & tro jé & ra. $\downarrow \mid$ & L \\
\hline
\end{tabular}




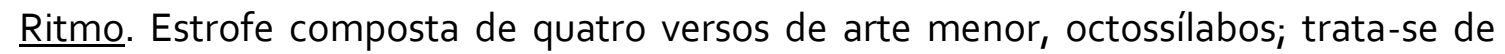
uma quarteta. Período rítmico interior:

- O $1^{\circ}$ verso é misto: 1 dactílico e 1 troqueu com anacrusa: o [ó o o/ ò o] (ó o.

- O $2^{\circ}$ verso: 2 troqueus, com anacrusa: o o [ó o / ò o (ó o.

- O $3^{\circ}$ verso: 2 dactílicos, com cesura, sem anacrusa: [ó o o/ ó o o] (ó o.

- O $4^{\circ}$ verso é misto: 1 troqueu e 1 dactílico, com anacrusa: o [ó o / ò o o] (ó o.

Rima soante, feminina e encadeada.

\section{9 La Infanzona de Medinica}

Doña Estefaldina teje su calceta,/ Puesta de mitones, cofia y pañoleta,/ En el saledizo de su gran balcón./ Dona Estefaldina nunca fué casada,/ Así que en la falda, de cintas picada,/Tres gatos malteses hacen el ron-ron.

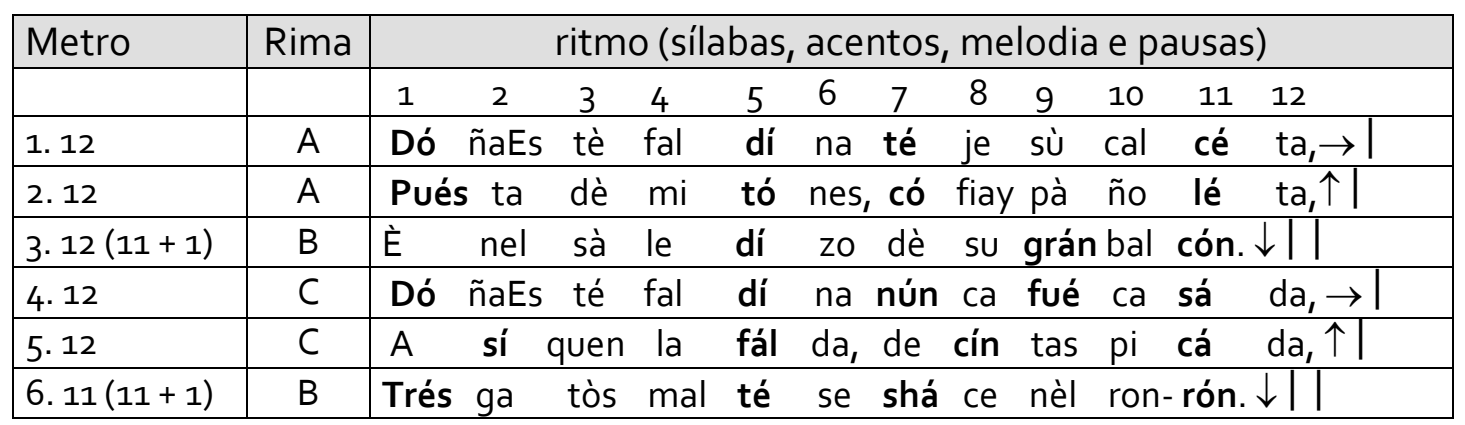

Ritmo. Estrofe composta de seis versos de arte maior: todos dodecassílabos, simétricos $(6+6)$, com acentos primários na primeira sílaba tônica de cada hemistíquio; trata-se de um sexteto oxítono (cf. 2.7). Período rítmico interior:

- O $1^{\circ}$ verso: 5 troqueus, sem anacrusa: [ó o/ ò o / ó o / ó o / ò o] (ó o.

- O 20 verso: 5 troqueus, sem anacrusa: [ó o / ò o/ó o / ó o / ò o] (ó o.

- O $3^{\circ}$ verso: 5 troqueus, sem anacrusa: [ò o/ ò o/ ó o / ò o / ó o] (ó.

- O $4^{\circ}$ verso: 5 troqueus, sem anacrusa: [ó o / ò o / ó o / ó o / ó o] (ó o.

- O $5^{\circ}$ verso consta de 3 dactílicos, com anacrusa; é o único verso que quebra o padrão trocaico, sem anacrusa, da estrofe: o [ó o o/ ó o o / ó o o] (ó o.

- O 60 verso: 5 troqueus, sem anacrusa: [ó o/ ò o / ó o / ó o / ò o] (ó.

Rima soante, feminina, masculina e interpolada.

\section{10 Tijeras abiertas}

Despertó doña Estefaldina./ ¡Soñó con tijeras abiertas!.../ Agorina/ Por el sueño desgracias ciertas. 


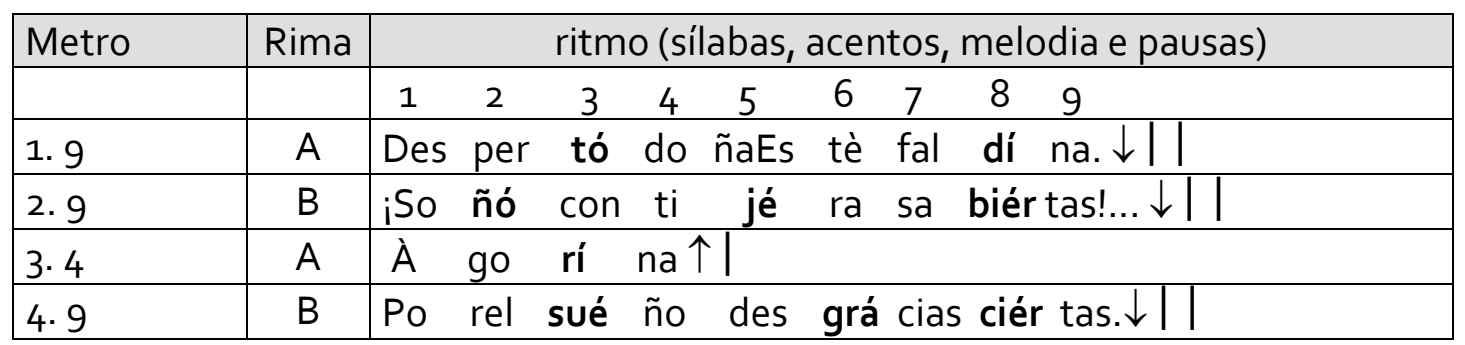

Ritmo. Estrofe composta de três versos de arte maior, eneassílabos, e um, de arte menor, tetrassílabo, de combinação métrica original $(9+9+4+9)$, pois foge aos padrões. Período rítmico interior:

- O $1^{\circ}$ verso é misto: 1 dactílico e 1 troqueu, com anacrusa: o o [ó o o / ò o] (ó o.

- O $2^{\circ}$ verso: 2 dactílicos, com anacrusa: o [ó o o / ó o o] (ó o.

- O $3^{\circ}$ verso: 1 troqueu, sem anacrusa: [ò o] ó o.

- $\mathrm{O} 4^{\circ}$ verso é o conjunto de 1 dactílico e 1 troqueu, com anacrusa, equivalente ao 10: o o [ó o o/ó o] (ó o.

Rima soante, feminina e encadeada.

\section{11 La coima}

El gato dormita en la silla, Da un círculo al techo el quinqué:/ La cornuda luz amarilla/ Dice en el cuarto su ananké.

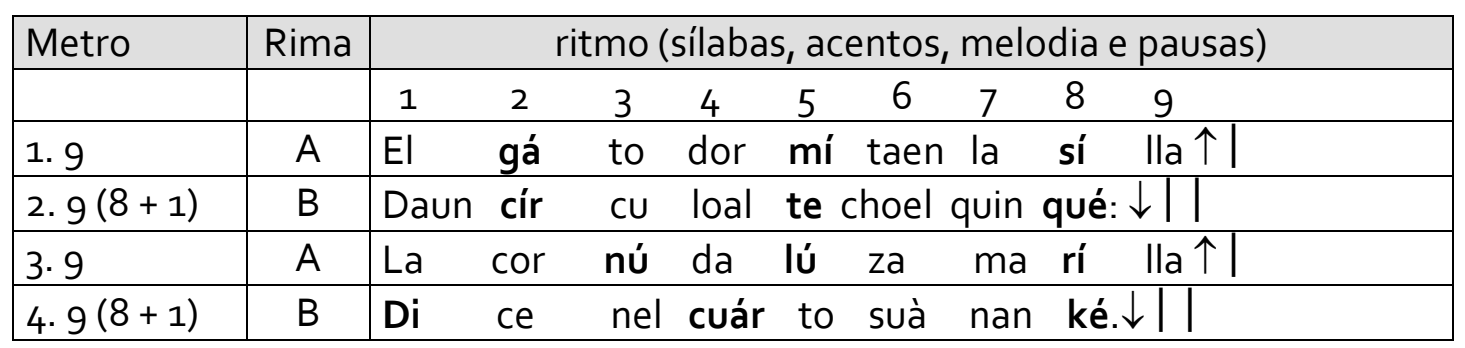

Ritmo. Estrofe de quatro versos, eneassílabos. O último verso é de "gaita galega" (acentos sobre $1^{\mathrm{a}}$ e $8^{\mathrm{a}}$ sílabas) (MASIP, 2002, p. 60). Período rítmico interior:

- O $1^{\circ}$ verso: 2 dactílicos, com anacrusa: o [ó o o / ó o o] (ó o.

- O $2^{\circ}$ verso: 2 dactílicos, com anacrusa, equivalente ao $1^{\circ}$ : o [ó o o / ó o o] (ó.

- O $3^{\circ}$ verso é misto: 1 troqueu e 1 dactílico, com anacrusa: o o [ó o / ó o o] (ó o.

- O $4^{\circ}$ verso é misto: 1 dactílico e 2 troqueus, sem anacrusa: [ó o o/ ó o / ò o] (ó.

Rima soante, feminina, masculina e encadeada.

\section{3. $12 \mathrm{El}$ preso}

Camino polvoriento del herrén amarillo/ Declinando la tarde. En la loma, un castillo. 


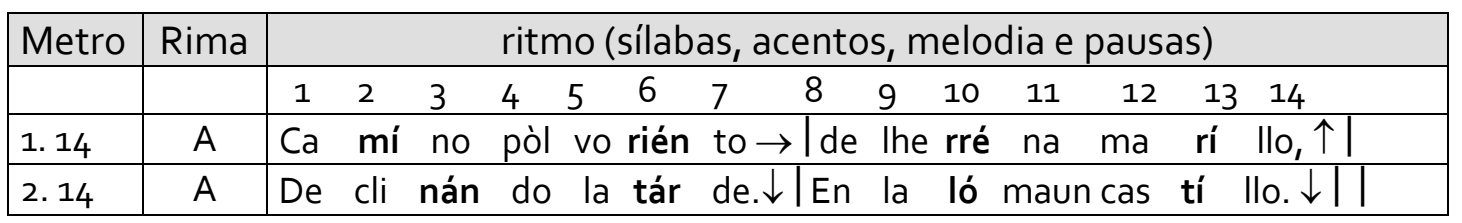

Ritmo. Estrofe de dois versos alexandrinos, isto é, de arte maior, tetradecassílabos, simétricos, distribuídos em dois hemistíquios heptassílabos (MASIP, 2002, p. 65-66). Período rítmico interior:

- $O 1^{0}$ verso é um conjunto de dois heptassílabos; o primeiro, composto de 2 troqueus e o segundo, de 1 dactílico, ambos com anacrusa: o [ó o/ ò o] ó o | | o o [ó o o] (ó o.

- $\quad 2^{\circ}$ verso é também um conjunto de 2 heptassílabos; ambos, compostos de 1 dactílico, com anacrusa: o o [ó o o] ó o | | o o [ó o o] (ó o.

Rima soante, feminina e emparelhada.

\section{13 Garrote vil}

Tan! jtan! ¡tan! Canta el martillo./ El garrote alzando están,/ Canta en el campo un cuclillo,/Y las estrellas se van/ Al compás del estribillo/Con que repica el martillo:/ itan! ¡tan! ¡tan!

\begin{tabular}{|c|c|c|}
\hline Metro & Rima & ritmo (sílabas, acentos, melodia e pausas) \\
\hline & & 6 \\
\hline 1.8 & A & ¡Tán! ¡tan! ¡tan! Cán tael mar tí $\|$ o. $\downarrow||$ \\
\hline $2.8(7+1)$ & $\mathrm{B}$ & rró teal zán does tán, $\downarrow \mid$ \\
\hline 3.8 & A & nel cám poun cu cli $\| l o, \uparrow \mid$ \\
\hline $4.8(7+1)$ & B & ses tré lla se ván $\rightarrow \mid$ \\
\hline 5.8 & A & com pás de \\
\hline 6.8 & A & Con que re pí cael mar tí $\| l o: \downarrow$ \\
\hline $7 \cdot 4(3+1)$ & B & ¡tán! ¡tan! ¡tán! $\downarrow \mid$ \\
\hline
\end{tabular}

Ritmo. Estrofe composta de sete versos de arte menor; seis, octossílabos e um, tetrassílabo; trata-se de uma sétima, resultado da junção de uma quarteta e de um terceto de pé quebrado (MASIP, 2002, p. 74). Período rítmico interior:

- O $1^{\circ}$ verso: conjunto de 2 dactílicos, sem anacrusa: [ó o o / ó o o] (ó o.

- O $2^{\circ}$ verso: conjunto de 2 troqueus, com anacrusa: o o [ó o / ó o] (ó.

- O $3^{\circ}$ verso: dois dactílicos, semelhante ao 1º, sem anacrusa: [ó o o / ó o o] (ó o.

- O $4^{\circ}$ verso: 1 dactílico, com anacrusa: 0 o o) [ó o o] (ó.

- O $5^{\circ}$ verso: 3 troqueus, com anacrusa: o o [ó o/ ò o ] (ó o.

- O 60 verso: 1 dactílico, semelhante ao $4^{\circ}$, com anacrusa: o o o [ó o o] (ó o.

- O $7^{\circ}$ verso: 1 troqueu, sem anacrusa: [ó o] (ó.

Rima soante, feminina, masculina e interpolada. 


\section{14 El crimen de Medínica}

Crimen horrible! Pregona el ciego./ Y el cuadro muestra de un pintor lego,/ Que acaso hubiera placido al Griego.

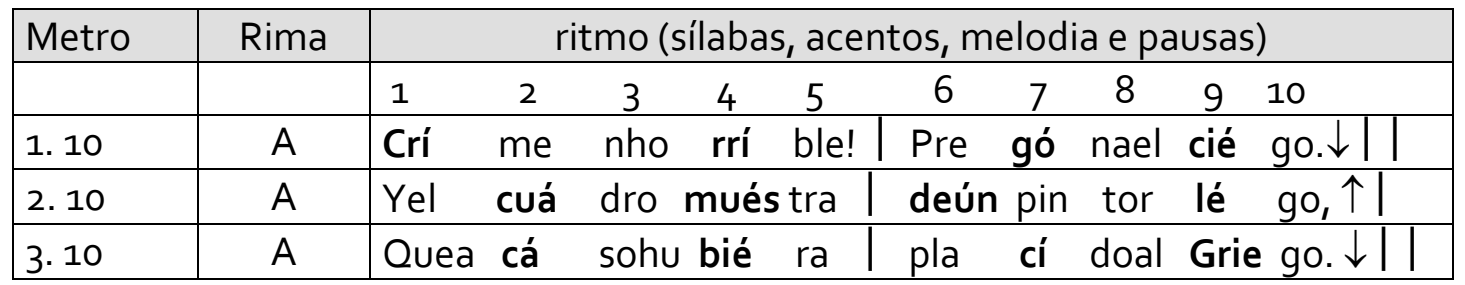

Ritmo. Versos de arte maior. Terceto de decassílabos gregorianos, composto de dois hemistíquios pentassílabos (MASIP, 2002, p. 61). Período rítmico interior:

- O $1^{\circ}$ verso: 2 dactílicos e 1 troqueu, sem anacrusa: [ó o o / ó o o / ó o] (ó o

- O $2^{\circ}$ é misto: 2 troqueus e 1 dactílico, com anacrusa: o [ó o / ó o / ó o o] (ó o.

- O $3^{\circ}$ é misto, 1 dactílico e 2 troqueus, com anacrusa: o [ó o / ó o o/ ó o] (ó o.

Rima soante, feminina e contínua.

\section{15 Vista madrileña}

La tarde calina:/ - iMojama y cecina!/ -iTorraets y altramuz!/ ¡Guardillas solares,/ Plenas de cantares,/ Con el micifuz/ Filo del tejado,/ El rabo quemado,/ Los ojos en luz!

\begin{tabular}{|c|c|c|}
\hline Metro & Rima & ritmo (sílabas, acentos, melodia e pausas) \\
\hline & & 5 \\
\hline 1.6 & A & La tár de ca lí na: $\downarrow \mid$ \\
\hline 2.6 & A & 一iMo já may ce cí na! $\downarrow \mid$ \\
\hline $3.6(5+1)$ & $\mathrm{B}$ & - iTo rra ét syal tra múz! $\downarrow$ \\
\hline 4.6 & C & ¡Guar dí lla so lá $\quad$ res, $\rightarrow$ \\
\hline 5.6 & C & Ple nas dè can tá res, $\uparrow \mid$ \\
\hline $6.6(5+1)$ & $\mathrm{B}$ & Cò nel mì ci \\
\hline 7.6 & $\mathrm{D}$ & Fí lo dèl te já $\quad$ do, $\rightarrow$ \\
\hline 8.6 & $\mathrm{D}$ & rá bo que má do, $\rightarrow$ \\
\hline $9.6(5+1)$ & $B$ & Lo $\quad$ só jo sen lúz! $\downarrow||$ \\
\hline
\end{tabular}

Ritmo. Estrofe composta de nove versos de arte menor: todos hexassílabos; trata-se de uma nona de arte menor (MASIP, 2002, p. 75-76). Período rítmico interior:

- O $1^{\circ}$ verso: 1 dactílico, com anacrusa: o [ó o o] (ó o.

- O $2^{\circ}$ verso: 1 dactílico, semelhante ao $1^{\circ}$ com anacrusa: o [ó o o] (ó o.

- O $3^{\circ}$ verso: 1 dactílico com anacrusa: o o [ó o o] (ó

- O $4^{\circ}$ verso: 1 dactílico, semelhante ao $1^{\circ}$ e ao $2^{\circ}$, com anacrusa: o [ó o o] (ó o.

- O $5^{\circ}$ verso: 2 troqueus, sem anacrusa: [ó o / ò o] (ó o. 
- O 60 verso: 2 troqueus, sem anacrusa: [ò o / ò o] (ó.

- O $7^{\circ}$ verso: 2 troqueus, sem anacrusa, semelhante ao 5: [ó o / ò o] (ó o.

- O $8^{\circ}$ verso: 1 dactílico, semelhante ao $1^{\circ}, 2^{\circ}$ e $4^{\circ}$, com anacrusa: o [ó o o] (ó o

- O go verso: 1 dactílico, com anacrusa: o [ó o o] (ó.

Rima soante, feminina, masculina e interpolada.

\section{16 Resol de verbena}

Ingrata la luz de la tarde,/La lejanía en gris de plomo,/ Los olivos de azul cobarde,/El campo amarillo de cromo.

\begin{tabular}{|c|c|c|c|c|c|c|c|c|}
\hline Metro & Rima & \multicolumn{7}{|c|}{ ritmo (sílabas, acentos, melodia e pausas } \\
\hline & & 1 & 3 & 5 & 6 & 7 & 8 & 9 \\
\hline 1.9 & A & $\ln$ & grá & la lúz & de & la & tár & $\mathrm{de}_{\mathrm{e}} \uparrow \mid$ \\
\hline 2.9 & B & La & ja & ní aen & grís & de & pló & $\mathrm{mo}, \downarrow 1$ \\
\hline 3.9 & A & Lo & so & vos dea & zúl & $\mathrm{CO}$ & bár & $\mathrm{de}, \uparrow \mid$ \\
\hline 4.9 & $B$ & El & cám poa & ma rí & Ilo & de & cró & mo. $\downarrow \mid$ \\
\hline
\end{tabular}

Ritmo. Estrofe composta de quatro versos, eneassílabos. Período rítmico interior:

- O $1^{\circ}$ verso: 2 dactílicos, com anacrusa: o [ó o o / ó o o] (ó o.

- O $2^{\circ}$ verso: 2 troqueus, com anacrusa: o o o [ó o / ó o] (ó o.

- O $3^{\circ}$ verso é misto: 1 dactílico e 1 troqueu, com anacrusa: o o [ó o o/ ó o] (ó o.

- O $4^{\circ}$ verso: 2 dactílicos, com anacrusa, equivalente ao $1^{\circ}$ : o [ó o o / ó o o] (ó o.

Rima soante, feminina e encadeada.

\section{17 La tienda del herbolario}

Aquella cueva del herbolario/Se me ofrecía como un breviario.

\begin{tabular}{|l|c|cccccccccc|}
\hline Metro & Rima & \multicolumn{1}{|c|}{ ritmo (sílabas, acentos, melodia e pausas) } \\
\hline & & 1 & 2 & 3 & 4 & 5 & 6 & 7 & 8 & 9 & 10 \\
\hline 1.10 & A & A & que & lla & cué & va & de & Ihèr bo & lá rio $\uparrow$ & $\mid$ \\
\hline 2.10 & A & Se & meo & fre & cí & a & co & moún bre viá rio. $\downarrow||$ \\
\hline
\end{tabular}

Ritmo. Versos de arte maior; uma parelha de decassílabos gregorianos, compostos de dois hemistíquios pentassílabos (MASIP, 2002, p.61). Período rítmico interior:

- O $1^{\circ}$ verso é misto: 1 dactílico e 1 troqueu, com anacrusa: o o o [ó o o / ò o] (ó o.

- O $2^{\circ}$ verso é misto: 1 dactílico e 1 troqueu, com anacrusa: o o o [ó o o / ó o] (ó o.

Rima soante, feminina e contínua. 


\section{18 Rosa del sanatorio}

Bajo la sensación del cloroformo/ Me hacen temblar con alarido interno,/ La luz de acuario de un jardín moderno,/Y el amarillo olor del yodoformo.

\begin{tabular}{|c|c|c|c|c|c|c|c|c|c|c|c|}
\hline Metro & Rima & \multicolumn{10}{|c|}{ ritmo (sílabas, acentos, melodia e pausas) } \\
\hline & & 1 & 2 & 3 & 5 & 6 & 7 & 8 & 9 & 10 & 11 \\
\hline 1. 11 & A & Bá & jo & là sen & sa & ción & del & clò & ro & fór & $\mathrm{mo} \rightarrow$ \\
\hline 2. 11 & $B$ & Mehá & cen & tem blár & & nà & la & rí & doin & tér & no, $\uparrow$ \\
\hline 3. 11 & B & La & lúz & dea cuá & rio & deún & jar & dín & mo & dér & no, $\rightarrow$ \\
\hline 3.11 & A & $\mathrm{Ye}$ & la & ma rí & Ilo & lór & del & yò & do & fór & mo. $\downarrow$ \\
\hline
\end{tabular}

Ritmo. Versos de arte maior. Estrofe de versos endecassílabos. Período rítmico interior (cf. 2.4):

- O $1^{\circ}$ verso é misto: 1 dactílico e 2 troqueus, sem anacrusa: [ó o / ò o o / ó o / ò o] (ó 0 .

- O $2^{\circ}$ verso é um endecassílabo a maiori, enfático (acentos sobre as sílabas 1, 4, 6, 8 e 10): conjunto de três troqueus, com anacrusa: [ó o o / ó o / ò o / ó o] (ó o.

- O $3^{\circ}$ verso é um endecassílabo a maiori heróico (acentos nas sílabas 2, 4, 6, 8, 10), conjunto de quatro troqueus, com anacrusa: o) [ó o / ó o / ó o / ó o] (ó o.

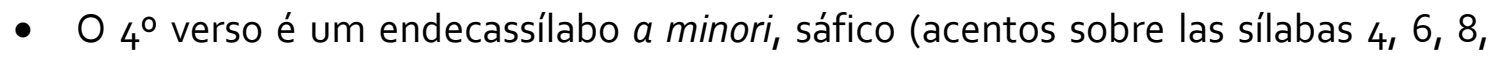
10), com anacrusa: o o o [ó o / ó o / ò o] (ó o.

Rima soante, feminina e interpolada.

\section{Conclusões}

La pipa de kif é uma coletânea de poemas que convidam a uma profunda reflexão. Surpreende, em primeiro lugar, a perfeição técnica: divisão silábica irretocável, rima sempre soante, por vezes masculina, feminina, abraçada, encadeada, interpolada ou contínua; metros dactílicos, troqueus ou mistos e ritmo equilibrado; a originalidade é o segundo traço característico de cada uma das composições: mesmo demonstrando total domínio dos metros, em momento algum Valle-Inclán se curva à tradição, fugindo sistematicamente de paradigmas consagrados como árias, baladas, canções, cosantes, cantatas, cantigas, doloras, églogas, elegias, endechas, epicédios, estâncias, hinos, idílios, letrilhas, liras, madrigais, prantos, serranas, silvas, sonetos, ou vilancetes; a terceira característica é a variedade: usa versos hexassílabos (em 3 poemas), octossílabos (em 5 poemas), eneassílabos (em 5 poemas), decassílabos (em 2 poemas), endecassílabos enfáticos, heroicos e sáficos (em 2 poemas), dodecassílabos (em 3 poemas) e tetradecassílabos (em 1 poema); e estrofes de dois 
versos (2), três versos (1), quatro versos (12), seis versos (2), sete versos (1), oito versos (1) e nove versos (1). Enfim, o poeta galego monta um festival estético, todo seu, mediante parelhas gregorianas e alexandrinas, tercetos, quartetas puras ou de pé quebrado, seguidilhas, redondilhas, coplas manriquenhas, sextetos, sétimas e nonas de arte maior e menor, para transmitir uma mensagem implícita, velada, mas evidente: Caro leitor: o autor desta coletânea é um poeta que domina a técnica do verso, sabe rimar, medir e ritmar, mas não se submete aos padrões estabelecidos. 
5 Referências bibliográficas

ALARCOS LLORACH, E. Fonología española. Madrid: Gredos, 1991.

ALI, M. S. Versificação portuguesa. São Paulo: EDUSP, 1999

BANDEIRA, M. Obras completas. Rio de Janeiro: Nova Aguilar, 1996

BARBOSA, F. Cinco séculos de poesía. São Paulo: Laudy, 2000.

BELLO. A. Opúsculos literarios y críticos. Santigo de Chile: G. Ramírez, 1883.

BONNIN, V., I. La versificación española. Barcelona: Octaedro, 1996

BOUSOÑO, C. Teoría de la expresión poética (2 vol.). Madrid: Gredos, 1985.

CUNHA, C.; CINTRA, L. Nova gramática do português contemporâneo. Rio: Nova Fronteira, 1985.

DARÍO, R. Antología Poética. Madrid: EDAF, 1981.

DIEGO, G. Cementerio civil. Barcelona: Plaza y Janés, 1972.

DOMÍNGUEZ C. J. Métrica española. Madrid: Síntesis, 1993.

ESPINOSA, P. (Org.) Flores de poetas ilustres. Sevilla: Fundación Lara, 2005.

GRAMMONT, M. Le vers français. Paris: Delagrave, 1937.

HERRERO, J. L. Métrica española, teoría y práctica. Madrid: Ediciones Oro, 1996.

JAMES FREYRE, R. Leyes de la versificación castellana. Buenos Aires: Coni, 1912. 
LÓPEZ , F. Métrica española del siglo XX. Madrid: Gredos, 1987.

MASIP, V. Manual de poesía española y portuguesa. Recife: Bagaço, 2002.

Fonologia y ortografía españolas. Recife: Bagaço, 2006.

Fonologia, fonética e ortografia portuguesas. Rio: GEN/LTC, 2014.

MATTOSO C., Jr. Para o estudo da fonêmica portuguesa. Rio: Padrão Editora, 1977.

MOISÉS, M. A criação literária. São Paulo: Cultrix, 2000.

MORRIS, Ch. Fundamentos da teoria dos signos. In: Problemas e métodos da semiologia. Lisboa: Edições 70, 1966.

NAVARRO TOMÁS, T. Métrica española. Madrid: Guadarrama, 1972.

OTERO, B. Antología (y notas). Vigo: Mensajes de Poesía, 1952.

OVIDIO. Tristia. Cambridge: Harvard University Press, 2018.

QUEVEDO, F. de. Poesía completa. Barcelona: Planeta, 1999.

. Antología poética. Madrid: Espasa. 2002.

QUILIS, A. Métrica española. Barcelona: Ariel, 1997.

.Tratado de fonología y fonética españolas. Madrid: Gredos, 1993.

La juntura en español. Un problema de fonología. Presente y futuro de la lengua española v. 1, 1981, p. 163-171.

SÁ MIRANDA. Poesias escolhidas. São Paulo: Itatiaia, 1970. 
SAUSSURE, F. Curso de Lingüística Geral. São Paulo: Cultrix, 2006.

TAVARES, H. Teoria literária. Rio: Vila Rica, 1996.

TOLEDO, G. A. El ritmo en el español. Madrid, Gredos, 1988.

VALLE-INCLÁN, R. M. del. La pipa de Kif. Madrid: SGEL, 1919.

i Vicente Masip Viciano é professor do Departamento de Letras da UFPE. vmv@terra.com.br

ii Oussama Naouar é professor do Departamento de Letras da UFPE.

onaovar@hotmail.com 